\title{
The Consideration of Obtaining Evidence System Reform: In the Perspective of Department of Forensic Science and Technology in the Public Security Bureau of China
}

\author{
Yanjun Liu $^{1}$ \\ ${ }^{1}$ China University of Political Science and Law, China \\ Correspondence: Yanjun Liu, Institute of Evidence Law and Forensic Science, China University of Political Science \\ and Law, Beijing 100088, China. E-mail: xsjszdlyj@163.com
}

Received: October 11, $2015 \quad$ Accepted: October 23, $2015 \quad$ Online Published: November 24, 2015

doi:10.5430/wjss.v3n1p7 URL: http://dx.doi.org/10.5430/wjss.v3n1p7

\begin{abstract}
As the department of forensic Science and Technology in basic public security organization in China, it often encounters a variety of practical and legal issues in the evidence obtaining process, which greatly restrict its functions in daily work. This article try to find the reasons in the aspect of institution, law, society, economy by illustrating the current circumstance and problems, such as legal problem, practical implement, institutional mechanisms. We also seek the suitable domestic reform path and propose the suggestions to promote the evidence obtaining innovation with the help of evidence law and other legal principle.
\end{abstract}

Keywords: Evidence obtaining system, Judicial proof, Public security bureau, Forensic Science and Technology, Physical evidence authentication

\section{Introduction}

As the department of forensic science and technology in basic public security organization in China, it often encounters a variety of practical and legal issues in the daily work, such as discovery, storage, authentication and identification of material evidence. We attribute the appearance of these problems to the following two aspects. Firstly, with the development and the advancement of society, plenty of authentication matters of difficult case have emerged. Secondly, the new criminal procedure law amends the category and validity standard of evidence. The emergence of these issues is not only the opportunities but also the challenges for us. On the one hand, forensic science and technology is widely applied to case investigation.On the other hand, it is helpful to overcome the limit from verbal evidence such as affidavits. It is also beneficial for the realization of rule of law in China. Most of our current injustices associated with torture.The mass emergency and wide application of forensic Science and Technology can prevent the occurrence of injustice to some extent.

Currently, the researches on authentication and identification by law are far from practical experience in grass-roots. There are many studies in theory which does not solve the problems. This article try to find the reasons in the aspect of institution, law, society, economy by illustrating the current circumstance and problems, such as legal problem, practical implement, institutional mechanisms. We also try to seek the suitable domestic reform path and propose the suggestions to promote the evidence obtaining innovation with the help of evidence law and other legal principle.

\section{The Summary of Evidence Obtaining in the Department of Forensic Science and Technology \\ 1.1 The Method and Concept of Evidence Obtaining}

Evidence obtaining is the special activities that investigators gather evidences, censor evidences preliminarily and keep evidences on the basis of law in order to find out the truth of case and prove the affirmation. This concept is equivalent to the narrow sense of evidence investigation.As the first part of judicial proof, evidence obtaining is always an investigation performance in the pre-trial process in order to obtain the unknown evidences.

In China, the method of evidence obtaining consists of various investigative measures which are stipulated by law or 
not, such as Inquiry, interrogation, identification, search, inspection, investigation testing, authentication, technical investigation and evidence keeping.These measures provide a guarantee for the evidence obtaining in judicial practice activities.

\subsection{The Category of Gathering Evidence in the Department of Forensic Science and Technology in Public Security Organization of China}

\subsubsection{Discovery, Gathering and Storage of Material Evidence}

The role of evidences in litigation has been widely recognized. The most important and basic task to maximize the function of them is to find them, to obtain them and keep them carefully.That is to say, discovery, gathering and storage of material evidence is the key prelude to develop the function.The process consists of packaging, preservation, transportation and management of evidences.

\subsubsection{Authentication and Identification of Material Evidence}

Authentication and identification of material evidence is a very complicated activity.In this process, the experts who have the basic theory and practical technology on the material evidence science, accept the assignment or hire to solve some special problems related to the evidence, such as the source of evidence, the formation of material evidence, the original situation, and so on.Then they must analyze and test the material evidence and related materials, and give a final or temporary judgment or opinion according to the evidences. In practice, the material evidence authentication and identification is divided into the following categories: verification of traces, forensic document examination, chemical evidence identification, biological evidence identification, audiovisual material identification, and electronic evidence identification. According to the different procedures, the identification can be divided into initial identification, supplementary identification, re-identification and co-identification, etc..

\section{Problems and Reform Necessity of Gathering Evidence in the Department of Forensic Science and Technology in Public Security Organization of China}

As a criminal technical personnel in the basic police bureau, in their daily work the author is always busy with criminal scene investigation, evidence collection, evidence storage and identification of specific kinds of evidences. I also encounter many problems or contradictions about evidence obtaining.

\subsection{Legal Issues of Evidence Obtaining}

\subsubsection{The Limitation of Obtaining Electronic Evidence and Network Right to Privacy}

Chongqing police announced that they cleared up the largest Q money theft case in May14, 2012. The key is advanced electronic means of evidence, and they timely investigate and seizure all electronic evidences of this case. This is not an isolated case.Either in the new criminal activities like hacker attack, the network virus, or in the the detection process of traditional criminal cases such as terrorist attack, murder, electronic evidence has become an indispensable part of all the investigation activities [4]. However, electronic evidence collection is not only a problem of computer or network technology, it also involves the dispute in the legal and ethical standards [5]. When the personal information of the network encounters country power, the legal rights and interests of citizens can easily be infringed, especially in the right of privacy. What is the negative impact of the electronic evidence on the protection of the network privacy? Is it worth paying the price in order to obtain public safety? How can we ensure the justification of electronic evidence? What restrictions should it be subject to? How to achieve the balance between investigation authorities by law to protect the social security order and the rights of citizens' privacy protection?

\subsubsection{The Legitimacy of Video Surveillance and the Protection of Citizen's Right of Privacy}

The video surveillance system has an important role in preventing crime. It can be used in terrorizing crime, finding clues or criminal suspects and providing relevant evidence. It even can react immediately, disposal of crime and to reduce the losses caused by the crime in scene. So it has a beautiful name called"sky-net", "sky-eyes".

Based on these functions, it can occupy an irreplaceable role in the field of security. However, the application of video surveillance system is not only to prevent and control crimes, to maintain social security, but also to protect the privacy of citizens from infringement. How to balance the relationship between public interest and citizen privacy, which has been a dilemma choice for video surveillance system, just like the Shanghai judge collective prostitution case which created a great sensation. Although analyzing the case from the public security organs, it seems to be a simply question that whether the subject of gathering evidence is legal or not. However, what the police should do in 
the investigation process of obtaining video information involves individual privacy if the person concerned refuse to provide the evidences? Is the video data admissible, and whether they can be the judge accepted?

\subsubsection{Human Rights Issues in DNA Sample Collection}

Xinhua net reported a rape case in July 20, 2004. In order to investigate a vicious rape murder, the police searched the murderer in 150 thousand people door by door ,from which they focused on 1748 people, and gave the 1262 people a DNA test.

Then, the police compared the suspect semen stains left in the crime scene with the blood samples task force submitted, found that the semen stain left in the scene is the same as a 36 year old man in Laohekou City. Eventually, the suspect was arrested. Although the technology has developed, you can use the STR and Y-STR database for family investigation, which can reduce the number of blood samples. But in the legal point of view, whether the police has power to make the DNA test of so many people only according to their subjective doubt without their consent. Whether those people have obligation to accept the police DNA test? Does the practice violate the human rights of citizens?

\subsubsection{Liability for Wrongs of Identification and Appraiser Protection System}

No appraiser can ensure that all identification documents they write have no flaws.Any expert is not certainty that the identification he did has no errors and even mistakes. Professor Zhang Baosheng also agree on this point, and call this phenomenon as "the mirror of evidence" in evidence law.Taking the municipal public security and judicial where author works for example, the author is engaged in forensic DNA identification. The identification center accept nearly 1000 cases, issue identification documents more than 500 copies a year. In addition, we also share criminal investigation and laboratory accreditation. The energy of each person is extremely limited. Thus mistakes are inevitable. But once a fault appears, it will bring about many problems. Can we the appearance of problem to negligence, failure, fault? How to determine the standard? Whose identification fault liability we should attribute to? Is it Identification institution, the first expert, the re-examiner or the authorized signatory? If they all have responsibility, how to allocate? From another point of view, whether we should pay more attention to establishing the protection system for the identification of people at the same time.

\subsection{Practical Operation of Evidence Obtaining}

\subsubsection{Arguement of Gathering and Testing Subject: Separation Principle between Gathering and Testing}

Taking the crime scene evidence obtaining for example, legal subject which participate in gathering evidence in scene investigation include both investigators and criminal technical personnel. So there will be two situations. In the first case, the evidence is obtained by the scene investigators and relevant and identification is performed by criminal technical personnel (laboratory staff). In the second case, both the collection and authentication of evidence are executed by the criminal technical personnel (laboratory staff). This is the separation principle between gathering and testing which the public security organs have been advocating.The first case is the "separation", the second case is "no separation". As far as I know, in Chinese public security system, especially at the grass-root level, the probability of the second case is far more than the first case. Which one is better? Should we completely adhere to the "separation" and abandon the "no separation"principle? What is the efficiency of the practical case and identification? I think this is not just the problem that the primary investigator and the appraisal personnel consider, moreover, it should attract the attention of high level leaders who actually formulate the principle.

\subsubsection{Efficiency and Cost Issues: Excessive Collection and Low Detection Rate of Evidence in Scene}

In scene investigation, investigators are required to make the exhaustive search, exploration and extraction, regardless of whether the evidence has relevance to the case, which leads to a serious problem. That is excessive collection of the scene evidence.Another case is that some of the evidences are lack of detection possibility, such as hair without follicles. It can not detect the nuclear DNA. But investigators still collect them for testing. On the one hand, this situation is influenced by the thought of excessive collection. On the other hand, they may not have enough professional knowledges.In addition, the contradiction between the testing success rate and the number of samples is also very prominent. That is to say, more samples will bring the lower detection success rate. How to improve the efficiency of authentication and identification? How to avoid the excessive collection of the scene evidence? How to avoid wasting a lot of national resources to save the human cost?That is a problem puzzled the author.

\subsubsection{Function of Testing Results: Abuse of DNA Technology}

There is a very common phenomenon now in the case investigation of the public security organs. If the suspects do 
not use a cellphone, they will hardly be caught; If there is no video surveillance near the scene, case clue will be hardly found. If the the police do not obtain scene DNA, the case will be hard to break. When the policemen reach the scene, they do not investigate, pay the visit,only wait for the collection of the biological material and other DNA test results. Excessive reliance on the so-called high-tech means will lose the subjective initiative and the routine investigation means. They even do not want to carry out traditional scene analysis. It is common that the police take the DNA test results of the biological evidence from the scene directly to solve the case. But completely dependence on DNA test results without their own analysis will result in the abuse of DNA technology.It will not only increase the workload of the identification personnel, but also waste national material resources. So it is necessary for us to think about how to prevent the abuse of DNA technology from the perspective of inspection and identification.

2.2.4 Media Excessive Exposure: The Conflict between Right to Learn the Truth of the Citizen and Investigation Means Confidentiality of the Police

"The policeman had been tracking, waiting in the vicinity of the suspect in order not to be perceived by suspect, finally gathered a cigarette the suspect smoked. After DNA testing the police confirmed the murderer". "The trace inspection personnel extracted a clear fingerprint in the POS machine suspect used. With the help of fingerprint database, the police found the suspect." We can see the picture in the TV program everyday. Audience ratings similar to the legal program in China are high. However, people sitting in front of the TV is not just ordinary people. Those who are potential high risk population than the ordinary people even put more attention than the police. The details of investigation means in the public security organs have exposed completely.Someone will say that I am making a fuss. This kind of program is just legal program with legal education. Besides, the citizens own the right to know. Then what is the degree of the right to know? On the premise of emphasizing investigation means confidentiality of the public security organ, which details of investigative techniques can be exposed to the public? What is the degree? How to solve the conflict between the right to know of citizens and the investigation means confidentiality of the public security organ?

\subsection{Institutional Mechanism Issues of Gathering Evidence}

\subsubsection{The Role of Department of Forensic Science and Technology in Basic Public Security Organization}

Criminal science and technology work go through the investigation, crime fighting and criminal proceedings. It is the important scientific and technological support for public security work. It is the significant means to safeguard the justice and social stability.It is also the vital means to obtain scientific evidence, find the suspect, ensure the quality of cases.It is an effective way to cultivate new growth points and to improve the combat effectiveness. To a certain extent, the level of criminal science and technology determines the ability of this area to combat crime, and even to control the social security situation. Although the criminal technology plays an important role in public security work, in our country, the criminal technology department is still under the criminal investigation department. Only a few of the provinces and cities are independent from the criminal investigation department, Taking the provincial level police units for example, only five criminal technology sector is independent to the criminal investigation department, such as Shanxi, Heilongjiang, Anhui, Fujian, Gansu, which account for less than 17 percent. The low degree of attention is obvious.

\subsubsection{Current Criminal Technology Management System}

With the continuous improvement of the national legal system, the role of criminal science and technology in public security work is more and more big, which is the trend of the times. However, the development of criminal technology and the rapid development of China's economy, the gap compared with other categories of science and technology is growing. And its role in the public security work and the status is very disproportionate. On the plight of the criminal technology, people tend to be attributed to the following aspects, lack of investment, no attention of leadership, responsibility of the technical staff, low technical level and instable team. According to the author, this is just a superficial phenomenon, not the crux. Technical policemen own the highest school calendar, the best quality and most knowledge content. But they play a meaningless role in the public security units in a long time. The reason why our country's criminal technology is not developed. To a large extent, it is because of its rigid management system of criminal technology.

The independence of the examination and authentication is severely limited under the present system. The independence of judicial authentication means the objectivity and impartiality of the judicial appraisal institution and the judicial expert. In order to ensure the objectivity and impartiality of the appraisal opinion, and independently in the judicial appraisal activities, the appraiser is in charge. Any units, social organizations and individuals can interfere, in addition to the legal supervision of the law. At this point, the relevant laws and regulations have existed. 
However, it is very common that the identification activity of the public security units is seriously limited by administrative orders. The independence of the identification are severely damaged.

\subsubsection{The Times of Identification, Multiple Identification and the Ownership of Final Identification}

Hunan Huang Jing naked died case is a very famous case in China in 2006. With the sentence of court, So far, the case finished officially which lasted for 40 months. The case was very complicated, and caused unprecedented concern about China's judiciary. The identification problem is undoubted the focus of attention of the parties, which is also the case for the key. In the case seven appraisal agencies are involved, 5 autopsies, a review of the text and a suspension of identification were made. Finally, we got 6 copies of identification documents. Repetitive identification and conflicting appraisal conclusion brought people confusion, controversy and thinking. The restrictions of identification times, multiple identification and the ownership of final identification have become the most urgent problem need to solve. It is indeed an indisputable fact that current criminal technical evidence obtaining system in China is a serious lag. Therefore, it is urgent to reform, to find a suitable criminal technology work evidence system for our own national conditions and the actual situation!

\section{The Consideration of Obtaining Evidence System Reform in Chinese Criminal Technical Department}

\subsection{To Seek the Legal Support of Evidence Obtaining Elements}

Collection or extraction is not just a technical problem. When the evidence is extracted from the human body such as DNA blood samples or when it refers to people such as video surveillance and electronic data, Even advanced, mature and reliable collection technology, it also tend to make the parties feel fearful, or disgusting. They are worried about the violations of human rights, just like privacy, reputation, portrait rights . This is related to the issue of the legality of evidence obtaining, so that the criminal technical staff is limited in their daily work. With the development of the rule of law in our country, these problems must be faced directly. The Criminal Procedure Law of the People's Republic of China, which was implemented in 2013, provides a legal basis for the collection of biological samples such as blood, urine and other biological samples. However, as mentioned in the previous rape case, a thousand people were on the investigation. Is the extraction of blood samples of these innocent people legal? It seems to be lack of specific provisions.

\subsection{To Strengthen the Scientific and Technology Feature of Evidence Obtaining}

With respect to the discovery, collection and storage of evidence, we have pay a lot of attention to its scientific and technical feature, in which our country's colleges and research institution have made a great contribution. Some textbooks and monographs of forensic science, more or less, include this section. Some forensic scientific and technical researchers also focus on the technical means of discovery, collection and preservation. But for the basic criminal technical personnel, this form is somewhat not down to earth.Institute of Forensic Science Ministry of Public Security P.R.C has formulated 79 copies industry standards, 20 copies national standard in last 20 years from 1993 to 2013. And in the aspect of improving the practical operation of the technical work, the most practical way is to participate in the training of the Ministry of public security. In the training courses, the teaching of national experts in different majors and technical exchanges with the national counterparts are helpful to the daily criminal technology work. So the best consideration of the evidence discovery, extraction, storage, inspection problem from the view of science and technology, is the combination of GB, industrial standard and new technology exchange and training for criminal science and technology work.

\subsection{To Put the Judgment Rule of Evidence before the Evidence Obtaining, and Play a Rational Role}

The problem of efficiency and cost is the conflict between excessive collection and the low detection rate of scene evidence. We can get some conclusions after analyzing. First, excessive collection bring us some bad consequences, not only a waste of manpower and material resources, but failure of getting good results. It is labor hard to little avail Second, we assumed DNA testing personnel energy as a constant value. And inspection personnel can only test 200 samples once. If after investigator's careful pre screening, they select to submit20 copies evidences with the strongest correlation. Even if the inspection staff did not detect the results in the first time, they will have the energy to carry out the second, the third detection, so that the success rate is greatly improved. In the light of the problems commonly existing in the practical work of the grass-roots public security units, the author thinks that whether we can put ahead the correlation rules of evidence to the investigation stage of scene investigation, evidence collection. This point has been reflected by 2012 criminal procedure law, Article 54. But in the use of the prefix of evidence examination and judgment, it should be noted that investigation stage, after all, is different from the trial stage. In the investigation stage we not only provide relevant and probative evidence for the trial stage, but also have an important 
responsibility to find out the facts and truth. So the usage should be moderate and reasonable. The investigators in the actual case should try to refine and figure out constantly. In short, we should avoid the situation of excessive collection, prompt the transition to the situation of reasonable collection.

\subsection{To Solve the Problems of Multiple Identification by Limiting the Times of Identification and Heighten Re-identification Valve}

The multiple identification is a special phenomenon which is different from repetitive authentication. The former refers to the identification of the same special issue to achieve the conclusion, and the latter includes identification of different appraisal agencies. It may also exist in the same identification requirements identified by the same identification institution and even the same identification expert. So these two kinds of identification own a certain cross relationship. But they are not the same.

Combined with Huang Jing case, the author considers that we should reform the judicial authentication management system in the relevant aspects.

First, we should limit the times of identification. For example, whether we can learn the essence and spirit of other legal fields,such as two-courts rule and two-level appellate system.

Second, we can improve the threshold of re-identification. It is in line with the requirements of the scientific and technical problems and the needs of judicial practice to limit the starting of the re-identification .

Third, we need pay attention to the efficiency of the identification, the cautious approach to re-identification. That is the attitude to solve the problem of repetitive identification, to overcome the shortcomings of multiple identification.

Fourth, whether it is appropriate to consider the level and ability of appraisal agencies, the industry influence, the reputation, qualifications and other factors of the identification experts to help resolve the final identification of the ownership problem.

In addition, scholars have pointed out that we should give court the decision right of starting the identification procedure. The appraiser must appear in court for cross examination. And the reason for adoption of authentication documents must be illustrated rationally by judge. Some scholars also propose to establish a scientific appraisal standards, the start standard of authentication to limit repetitive identification. Some of these methods have been adopted in the reform of judicial identification and achieved some results. Some of them are expected to be further tested in practice.

\subsection{To Heighten Quality and Reliability of Evidence Identification}

\subsubsection{Effective Control of Identification Activity and Forensic Units: China National Accreditation Service (CNAS)}

Laboratory accreditation is a third-part attestation to a laboratory conveying formal demonstration of its competence to carry out specified testing, measurement and calibration. CNAS provides a means of determining, recognizing and promoting the competence of laboratories, thus providing a ready means for customers to access reliable testing and calibration services. CNAS also provides accreditation service for relevant facilities, such as Reference Material Producers and Providers of Proficiency Testing Schemes. In particular, in September 2013 the implementation of the Accreditation Criteria for the Competence of Forensic Units (CNAS-CL08) is a special criteria for the judicial identification and forensic science laboratories. Laboratory accreditation includes the following main contents: identification personnel and management, identification facilities, equipment, reagents, reference substances and environmental conditions, management system, etc. The author's public security judicial authentication center has been approved by the laboratory accreditation in August 2011. The laboratory accreditation is helpful to improve the management and inspection of the laboratory. But we should prevent the laboratory accreditation activities from becoming formalistic.

\subsubsection{To Guarantee the Independence of Forensic Units and Experts}

The principle of independence in the judicial appraisal activities is decided by the special nature of the science and technology and the the conclusion of authentication.

In essence, the judicial authentication is the activity in which the appraiser provides the evidence material. Such activity must be carried on independently in order to ensure the objectivity, the scientificalness, the authenticity, the impartiality of the appraisal conclusion. The independence of identification is the guarantee to the objectivity and impartiality of the appraisal conclusion.

\subsubsection{To Understand and Utilize Separation Principle between Evidence Gathering and Testing}

Separation principle between evidence gathering and testing has its benefits. The examination and appraisal 
personnel is equivalent to accept the "blind test" when they face the material evidence. Because he did not know the position and relationship with other evidence in the scene, there will be no preconceived appraisal methods, and test results are objective. But there is a natural defect using this way, that is the test of the samples is random, no targeted. If the detection personnel participate both in the scene investigation and in evidence extraction. The process does not separate, then in the detection he can accomplish authentication explicitly. They can both save time and improve the success rate of the test. So the author believes that the use of a principle can not blindly and completely rule out another principle. We should properly understand and make reasonable application.

\subsubsection{To Strengthen the Supervision of Authentication Institutions}

The principle of judicial independence and the legal supervision are not contradictory. They are restrict and promote each other. The common purpose is to ensure the objectivity and fairness of the appraisal activities and results. In many regulations and law of judicial authentication, the judicial identification and authentication activities should accept the supervision from the state, society, the litigant and client units. The whole process of the judicial identification is full of the appraisal supervision, which is reflected in all aspects. Such as the supervision of the legality of the identification procedures, the identification standard, the standardization of identification documents, the professional ethics of appraiser.

\subsection{To Reinforce the Management and Training of Public Security Criminal Technical Staff}

\subsubsection{Transformation of Traditional Ideas}

Investigation is not only the basis of the trial, but also the basis of the quality of the case. Since January 1, 2013, the new criminal procedure law officially have began to implement. The amendment of the criminal procedure law is a major event in the development of the criminal procedure advancement. The new criminal procedure law explicitly wrote "respect and protection of human rights" into the general principles. It also established the principle of not be forced self-incrimination. On the basis of this system we improve the system of investigation and evidence collection. Therefore, investigation personnel of public security units including criminal technical personnel should make a transformation in ideology from the investigation center to the trial center, from capturing suspects to getting evidences. With the help of the new criminal procedural law implement, we need push into the investigation and evidence collection system reform, continue to improve the capacity and level of investigation and evidence collection.

\subsubsection{Strict Requirements for the Appraiser}

The appraiser is the main body of identification. It is without any doubt that he played an important role in the identification activities. In order to ensure the quality and reliability of evidence identification, we should emphasize the management of the appraiser. In light of relevant law and combing the police practice,the Ministry of Public Security formulated the appraiser registration management regulation in public security units, to fight crimes, protect the people, maintain social security and stability and the judicial justice. Furthermore, we need establish a sound control mechanism. The relevant provisions of the Supreme People's Court and the Ministry of Justice shall have some implications for the management of identification in the public security units in some ways.

\subsubsection{To Solve the Treatment of Identification Experts in Time}

We need do a good service for the identification experts to solve their worries about the quality and reliability of evidence identification. In recent years, the country has paid more and more attention. The central government will develop and introduce professional and technical, administrative law enforcement civil service management regulations this year. It is currently working on the development of civil service pay system reform program. The direction of reform will be put to improving the treatment of grass-roots civil servants. There are two main tasks. One is to regulate additional allowance system, narrow the incomes gap between different regions. The other is to improve the parallel positions and system, connect ranks with wages treatment.

\subsubsection{To Promote Two-way Communication System}

In recent years, the Supreme People's Court choose 127 people from high, intermediate and basic people's court, have introduced 22 people from the relevant scientific research institutes, law schools and law firm such as famous law professor, associate professor and excellent lawyer etc, and have recruited 70 people from the college consisted of the JD and postdoctoral. This is selection system the implemented by supreme court. Inspired by this, the author believes that strengthening the training of forensic awareness can promote two-way election system. On the one hand, Law school graduates perform practical evidence investigation in the basic police station. On the other hand, the policeman with basic practical experience go back to law school to study evidence law. 


\section{References}

Huang Weizhi. (2006). Research on Forensic Evidence System (p. 206). Chinese Procuratorate Press.

Li Xuejun. (2010). On Physical Evidence: Criminalistics and Procedure Law Perspectives (p .67). China Renmin University Press.

Liu Jingkun. (2012). Implement the new criminal procedure law to reform the investigation evidence system. Retrieved from http:/www.cpd.com.cn/epaper/rmgab/2012-12-30/03b-1.html

Shen Deyong. (2005). Some suggestions on deepening the reform of judicial appraisal system. Retrieved from http://www.chinalawedu.com/news/20800/21690/2005/2/li17692059341612500235850_159712.htm

Tong Jinghai. (2014). Hebei will promote the civil service classification reform this year. Retrieved from http://rencai.people.com.cn/n/2014/0221/c244800-24424720.html

Wang Xiaolei. (2012). The discovery of biggest Q money criminal industrial chain. Retrieved from http://legal.people.com.cn/GB/17886331.html

Wei Lina, \& Li Zhaotao. (2005). Deputy to the National People's Congress consider that multiple identification prevent the judicial justice. Retrieved from http://news.sina.com.cn/c/2005-03-04/01485980971.shtml

Zhang Fang, \& Zhang Yunquan. (2005). Preventing repetitive identification in procedural program. Chinese Journal of Forensic Science, 4, 26.

Zhang Xianguo, \& Fu Junqing. (2004). The rape and murder suspect Zhang Guangqi are arrested in HuBei. Retrieved from http://news.xinhuanet.com/legal/2004-07/20/content_1617537.htm

Zhang Baosheng. (2009). Evidence Law. China University of Political Science and Law Press.

Zou Rusheng, \& Xia Hongtao. (2002). On the Existing Problems and Reform Conception in the Current Administrative System of Criminal Technology. Journal of HuBei Police Officer College. 3, 39. 